\title{
Conservatively treated patients with cerebral arteriovenous malformation: mental and physical outcome
}

\author{
ERLING BO ANDERSEN, JøRGEN PETERSEN, ERIK LYKKE MORTENSEN, \\ HANNE UDESEN
}

From the Department of Neurology, Glostrup University Hospital, Copenhagen, Denmark

SUMMARY Twenty five patients with conservatively treated cerebral arteriovenous malformation were followed up for a mean of $\mathbf{1 0 . 6}$ years after diagnosis. The follow up included neuropsychological examination. Bleeding did not occur after the time of diagnosis. Three patients had moderate to severe neurological deficits, five had moderate to severe intellectual impairment. Nineteen had an unaffected occupational status. It is concluded that the outcome in conservatively treated patients may be no worse than in surgically treated patients.

Surgical versus conservative treatment of cerebral arteriovenous malformation (AVM) is still a matter of dispute. According to Svien and $\mathrm{McRae}^{1}$ conservative treatment is appropriate for $80 \%$ of the patients. Yet in many centres the proportion of the surgically treated is substantially larger, from about $35 \%$ to $90 \%{ }^{2-9}$ (table 1). In the Cooperative study ${ }^{10}$ the rate of surgically treated patients was about $45 \%$ of 415 AVMs. With refinement of the surgical technique this proportion may increase.

Results of follow-ups, some of which are shown in table 1, are difficult to interpret, partly because of different selection criteria and differences in analysis.

Address for reprint requests: Erling Bo Andersen, Department of Neurology, Hvidovre Hospital, DK-2650 Hvidovre, Denmark.

Received 18 December 1987 and in revised form 5 April 1988. Accepted 11 April 1988.

Table 1 Results of previous studies
Rational guidelines in the form of decision analysis for the management of AVM have been proposed. ${ }^{6} 11$

An important aspect in the choice of treatment is the insufficient knowledge of the natural history of the disease. Prospective studies are not feasible because of the relative rarity of AVM. The conservatively treated patients who have been followed up, were usually considered unfit for operation for reasons such as the possibility for a poorer outcome for this group of patients than for the surgically managed group. Thus unknown selection factors may influence the results. The more specific conditions which have been emphasised are the risk of haemorrhage, rehaemorrhage, epilepsy, neurological deficit and death, as mentioned for instance by Graf et $a l^{12}$ and Crawford et al. ${ }^{13}$

An important although not thoroughly examined aspect concerning the natural history of the disease is the risk of developing cognitive disturbances. In some studies qualitatively estimated cognitive dis-

\begin{tabular}{|c|c|c|c|c|c|c|c|}
\hline \multirow{2}{*}{ Author } & & \multirow{2}{*}{$\begin{array}{l}\text { Op./unop. } \\
\text { No of cases }\end{array}$} & \multirow{2}{*}{$\begin{array}{l}\text { Follow up } \\
\text { years }\end{array}$} & \multicolumn{4}{|c|}{ Outcome (\%) } \\
\hline & & & & \multicolumn{2}{|l|}{ Operated } & \multicolumn{2}{|c|}{ Unoperated } \\
\hline $\begin{array}{l}\text { Troupp } \\
\text { Moody }^{2} \\
\text { Morello } \\
\text { Trumpy }^{4} \\
\text { Pelletieri }^{6} \\
\text { Guidetti }^{7} \\
\text { Abad }^{8} \\
\text { Fults }^{9}\end{array}$ & $\begin{array}{l}1965 \\
1970 \\
1973 \\
1977 \\
1980 \\
1980 \\
1983 \\
1984\end{array}$ & $\begin{array}{c}40 / 60 \\
97 / 8 \\
88 / 44 \\
42 / 47 \\
119 / 47 \\
95 / 50 \\
70 / 42 \\
48 / 83\end{array}$ & $\begin{array}{l}5.2 \text { mean } \\
>3 \\
1-22 \\
9.1 \text { mean } \\
10.5 \text { mean } \\
2-25 \\
4.8 \text { mean } \\
8.2 \text { mean }\end{array}$ & $\begin{array}{c}\overline{22} \\
7 \\
21 \\
15 \\
80^{*} \\
3 \\
6\end{array}$ & $\begin{array}{r}-14 \\
9 \\
12 \\
13 \\
6 \\
12 \\
19\end{array}$ & $\begin{array}{c}13 \\
0 \\
18 \\
21 \\
36 \\
57^{*} \\
41 \\
3\end{array}$ & $\begin{array}{l}14 \\
20 \\
18 \\
19 \\
17 \\
20 \\
20 \\
23\end{array}$ \\
\hline
\end{tabular}

Op. = operated. Disability in percentage of operated and unoperated groups. *All degrees of disability included. 
turbances have been reported, as by Svien and McRae $^{1}$ and Lange-Cosack. ${ }^{14}$ Systematic neuropsychological examination has been carried out in only a few studies. Thus Waltimo and Putkonen ${ }^{15}$ reported psychological test results of 40 patients with intracerebral or meningeal AVM. Presumably the test was performed shortly after the onset of symptoms, except in patients with initial haemorrhage when the test was postponed 4 years. It is not clear whether some of the patients underwent operation before the testing. Constans and Assal ${ }^{16}$ examined six patients with surgically treated AVM, three of these before surgical intervention. Finally Carter $e t$ al $^{17}$ reported psychological examination of an AVM patient with intellectual impairment prior to and improvement following excision of AVM. The purpose of the present study is to evaluate the physical, mental and social status of a mainly nonselected group of conservatively treated patients with AVM, the mental condition being assessed by neuropsychological testing.

\section{Material and methods}

\section{Patients}

From the record files in the Copenhagen county hospitals, Gentofte and Glostrup, we identified all patients fulfilling the following criteria.

(1) Intracerebral arteriovenous malformation proved by arteriography (or by necropsy if death from subarachnoid haemorrhage occurred before arteriography was performed) and without coexisting arterial aneurysms.

(2) Time of diagnosis from 1 January 1960 to 31 December 1979.

(3) Permanent address in the Copenhagen county at the time of diagnosis $(600,000$ inhabitants).

A total of 47 patients fulfilled the criteria. Excision of the AVM was performed or attempted in nine patients. Eight of these underwent surgery because of concomitant intracerebral haematoma (actually excision was performed on four patients and ligation of feeding vessels on two). Only one patient underwent elective excision in a hospital outside the county. Three died shortly after the onset of symptoms, all from the initial subarachnoid haemorrhage (SAH). Five of the remaining 35 patients died more than one year after diagnosis, but before the follow-up. One died from SAH, and one in status epilepticus. The cause of death in one patient was unrelated to AVM, and in two was unknown. One patient could not be traced.

Thus 29 unoperated patients were alive at follow-up. Four of these patients refused participation, but we were informed that two were well without physical or mental handicaps, one received disablement pension, and one was intellectually impaired but otherwise healthy. The remaining 25 unoperated patients participated in the follow-up. This reexamination group consisted of 14 males and 11 females. Mean age at the onset of symptoms was 29 years (range 4-63 years). Mean duration from the onset of symptoms to diagnosis was 4 years (range $0-46$ years). Mean duration from the onset of symptoms to follow-up was 15 years (range 4-60 years). Mean age at the follow-up was 44 years (range 19-71 years).

\section{Neurological evaluation}

At the re-examination an accurate neurological history was taken and physical and neurological examination carried out. CT and intravenous radionuclide angioscintigraphy were performed. Scintigrams and CT scans have been presented in a previous report. ${ }^{18}$

\section{Neuropsychological evaluation}

The neuropsychologists undertook the neuropsychological investigation without knowledge of the results of the neurological/physiological studies. The two psychologists tested 10 and 15 patients respectively.

The psychological investigation consisted of a clinical interview and a thorough neuropsychological testing. The purpose of the interview was to obtain information on the patients' background (educational and occupational career) and current condition (neuropsychological symptoms and occupational status). As a part of the interview the patients answered a questionnaire about neuropsychological symptoms.

Three kinds of psychological tests were used. (1) Tests to evaluate intelligence (including subtests of the verbal part of the WAIS). (2) Tests to evaluate possible general impairment in intellectual functioning (including the complete standard neuropsychological battery from the Copenhagen University Hospital, Rigshospitalet). ${ }^{19}$ (3) Tests to evaluate possible dysfunctioning in specific cognitive areas (including memory tests, tests for aphasia, and visuo-spatial tests).

The patients were very heterogenous with respect to background variables like education, age and disease story, and therefore the neuropsychological evaluation was based on both clinical judgment and a comparison with the results of a study of normal Danish subjects. ${ }^{20}$ The two psychologists discussed and agreed upon a final evaluation of all patients. This evaluation included an estimation of intelligence, general intellectual impairment and symptoms of specific dysfunctioning in visuo-spatial and verbal tests.

\section{Results}

The localisation and size of AVMs were assessed by arteriography (small: diameter $<2 \mathrm{~cm}$; medium: diameter $2-4 \mathrm{~cm}$; large: diameter $>4 \mathrm{~cm}$ ). The results are summarised in table 2 and correlated to the three types of symptom onsets, namely intracranial haemorrhage (SAH/intracerebral haematoma), epilepsy and neurological deficits (usually hemiplegia or aphasia).

At the time of onset of symptoms, three patients had slightly affected consciousness (11-12 on the Glasgow coma rating scale) and two patients had more pronounced affection (4 respectively 6 on the Glasgow coma rating scale). Within 6 days the level of consciousness was normal in all patients.

The AVM was diagnosed at the onset of symptoms in 12 of 13 patients with initial SAH. One was diagnosed after a rehaemorrhage 7 years later. Four patients with initial SAH later developed epilepsy. Epileptic seizures were the first symptom in eight patients. Two of these later suffered from SAH and one developed a hemiparesis. Neurological deficits 
Table 2 Data of 25 conservatively treated patients with AVM

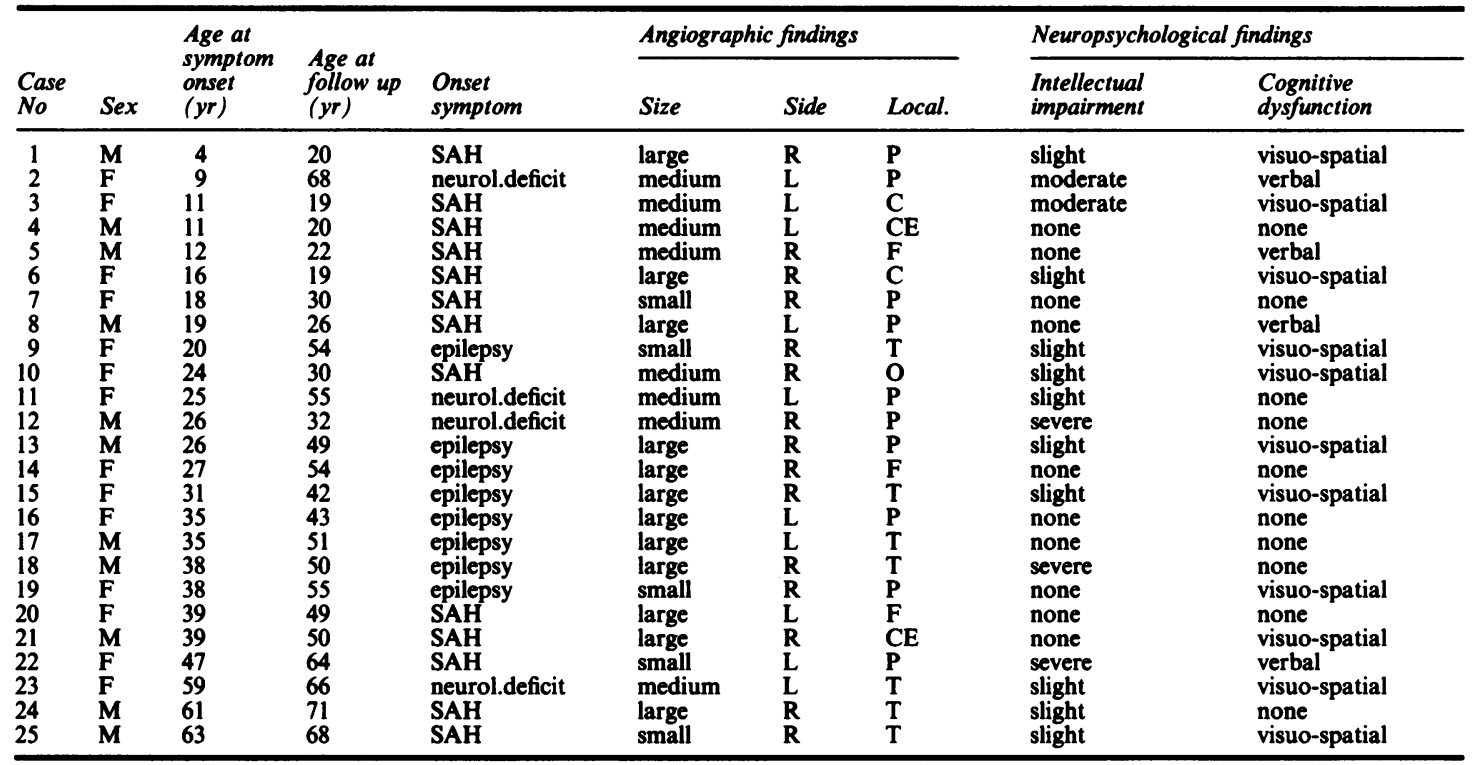

SAH = subarachnoid haemorrhage. $R=$ right. $L=$ left. $\mathbf{F}=$ frontal. $T=$ temporal. $\mathbf{P}=$ parietal. $\mathbf{O}=$ occipital. $C=$ central $($ deep structures). $\mathrm{CE}=$ cerebellar.

were the mode of presentation in four patients. Two of these later developed SAH and one developed epilepsy. During the period from diagnosis to the followup (264 patient-years) no episodes of SAH occurred.

\section{Neurological status}

Neurological symptoms at follow-up are described in table 3 (patients with previous epilepsy but without seizures during the last 5 years are not included in the group suffering from epilepsy). The epilepsy was adequately treated in all patients and the frequency of seizures was less than one every 6 months. Three patients showed moderate to severe neurological deficits. Eleven patients had neither epilepsy nor neurological deficits. CT and angioscintigraphy were not able to detect the small AVMs (lesions with a

Table 3 Symptoms at follow up in relation to symptom onset

\begin{tabular}{lllll}
\hline & \multicolumn{4}{l}{ Follow up symptom } \\
\cline { 2 - 5 } & & \multicolumn{4}{l}{ Neurological deficits } \\
\cline { 2 - 5 } \cline { 3 - 4 } Onset symptom & Epilepsy & Slight & Moderate & Severe \\
\hline Haemorrhage (13) & 3 & 3 & 1 & 1 \\
Epilepsy (8) & 5 & 3 & 0 & 0 \\
Neurological & & 0 & 0 & 1 \\
deficits (4) & $\mathbf{8}$ & 9 & 1 & 2 \\
\hline
\end{tabular}

The total number of patients with each onset symptom in brackets. diameter less than $2 \mathrm{~cm}$ on the original arteriograms).

CT showed cerebral infarct in 7, localised atrophy in 5 , diffuse atrophy in 5 and hydrocephalus in 1 patient. As mentioned above, these results have been elaborated and discussed in detail in a previous article. ${ }^{18}$

Neuropsychological status

The intelligence level of eight patients was estimated to be above average, the level of 14 patients was average, and the level of the remaining three patients was estimated to be below average.

Evaluated on this background five patients showed signs of severe general intellectual impairment. Of the remaining patients 10 had symptoms of slight impairment while 10 showed no signs of intellectual impairment.

In table 4 intellectual impairment is related to factors that may be important for the development of this condition. Onset symptoms, level of consciousness at onset/time of diagnosis, size and localisation of AVM, onset age, and duration from onset to follow-up. No obvious correlation between these variables was found. In all the five patients with severe general intellectual impairment CT showed positive findings. Three patients had diffuse cerebral atrophy, one patient had hydrocephalus, and one patient had sequelae from cerebral infarction. In two of the remaining 20 patients $C T$ showed diffuse cerebral atrophy, but these patients showed no signs of general intellectual impairment. Using the evaluation of 
Table 4 Intellectual impairment in relation to different disease parameters

\begin{tabular}{|c|c|c|c|c|c|}
\hline & \multicolumn{5}{|c|}{ General intellectual impairment } \\
\hline & None & Slight & Moderate & Severe & Total \\
\hline $\begin{array}{l}\text { Onset symptom } \\
\text { Haemorrhage } \\
\text { Epilepsy } \\
\text { Neurological deficits }\end{array}$ & $\begin{array}{l}6 \\
4 \\
0\end{array}$ & $\begin{array}{l}5 \\
3 \\
2\end{array}$ & $\begin{array}{l}1 \\
0 \\
1\end{array}$ & $\begin{array}{l}1 \\
1 \\
1\end{array}$ & $\begin{array}{r}13 \\
8 \\
4\end{array}$ \\
\hline $\begin{array}{l}\text { Consciousness } \\
\text { (at onset/diagnosis) } \\
\text { Normal } \\
\text { Slightly affected } \\
\text { Severely affected }\end{array}$ & $\begin{array}{l}8 \\
2 \\
0\end{array}$ & $\begin{array}{l}8 \\
1 \\
1\end{array}$ & $\begin{array}{l}2 \\
0 \\
0\end{array}$ & $\begin{array}{l}2 \\
0 \\
1\end{array}$ & $\begin{array}{r}20 \\
3 \\
2\end{array}$ \\
\hline $\begin{array}{l}\text { Size of AVM } \\
\text { Small } \\
\text { Medium } \\
\text { Large }\end{array}$ & $\begin{array}{l}2 \\
2 \\
6\end{array}$ & $\begin{array}{l}2 \\
3 \\
5\end{array}$ & $\begin{array}{l}2 \\
0 \\
0\end{array}$ & $\begin{array}{l}1 \\
1 \\
1\end{array}$ & $\begin{array}{r}7 \\
6 \\
12\end{array}$ \\
\hline $\begin{array}{l}\text { Localisation } \\
\text { Right } \\
\text { Left }\end{array}$ & $\begin{array}{l}5 \\
5\end{array}$ & $\begin{array}{l}8 \\
2\end{array}$ & $\begin{array}{l}0 \\
2\end{array}$ & $\begin{array}{l}2 \\
1\end{array}$ & $\begin{array}{l}15 \\
10\end{array}$ \\
\hline $\begin{array}{l}\text { Age }(y r) \text { at onset } \\
\leqslant 20 \\
21-40 \\
>40\end{array}$ & $\begin{array}{l}4 \\
6 \\
0\end{array}$ & $\begin{array}{l}3 \\
4 \\
3\end{array}$ & $\begin{array}{l}2 \\
0 \\
0\end{array}$ & $\begin{array}{l}0 \\
2 \\
1\end{array}$ & $\begin{array}{r}9 \\
12 \\
4\end{array}$ \\
\hline $\begin{array}{l}\text { Years from onset to } \\
\text { follow up } \\
3-9 \\
10-19 \\
\geqslant 20\end{array}$ & $\begin{array}{l}2 \\
7 \\
1\end{array}$ & $\begin{array}{l}4 \\
3 \\
3\end{array}$ & $\begin{array}{l}1 \\
0 \\
1\end{array}$ & $\begin{array}{l}1 \\
2 \\
0\end{array}$ & $\begin{array}{r}8 \\
12 \\
5\end{array}$ \\
\hline Total & 10 & 10 & 2 & 3 & 25 \\
\hline
\end{tabular}

visuo-spatial and verbal functions, the patients were classified into three groups. One group with visuospatial dysfunctions, one with verbal dysfunctions, and finally patients with no signs of specific dysfunctions. In 15 patients the AVM was in the right side of the brain and in 10 in the left side. Of the patients with right-sided AVM nine had visuo-spatial dysfunctions and of the patients with left-sided AVMs three had verbal dysfunctions. Perhaps it is more remarkable that of the 15 patients who actually had specific dysfunctions, only three patients showed dysfunctions that were not in agreement with traditional assumptions about hemispheric functions.

\section{Occupational status}

Table 5 shows that occupation was unaffected by AVM in 19 patients. Of these patients 11 were fulltime employed, one was part-time employed, one was a housewife, two were unemployed, three were students, and one was receiving old age pension. Six patients received disablement pension because of AVM. Two of these patients received the pension because of purely physical handicaps while four of the patients received the pension because of both physical and mental dysfunctioning.

Of the patients with severe intellectual impairment two received disablement pension, one had no employment, one was a student (secondary school level), and one was an unskilled worker. The last mentioned patient and one who received pension had
Table 5 Occupational status before and at follow-up

\begin{tabular}{lcc}
\hline & Before diagnosis & At follow-up \\
\hline Full time & 12 & 11 \\
Part time & 2 & 1 \\
Housewife & 3 & 1 \\
Unemployed & 0 & 2 \\
Disablement pension & 1 & 6 \\
Old age pension & 0 & 1 \\
Education & 7 & 3 \\
\hline
\end{tabular}

a history of drug and alcohol abuse, and this may of course be a partial or full explanation of the bad results in the neuropsychological testing.

\section{Discussion}

Cerebral arteriovenous malformation is a relatively rare abnormality. In the present material the incidence was 47 of 600,000 inhabitants in the county of Cophenhagen during 20 years $(0 \cdot 4 / 100,000 /$ year $)$. Only nine of the patients were operated on (eight because of intracerebral haematoma). Compared with other studies our group of conservatively treated patients must be considered relatively unselected, since elective extirpation of AVM was performed in only one patient (in a hospital outside the county).

The incidence, sex, size and localisation of AVM and type of initial symptom do not differ from the results of other studies. Because of the relatively small number of patients, a statistical analysis of the correlations between the anatomical characteristics and the physical symptoms has not been performed.

The essential purpose of the present study was to evaluate the longterm risk of developing intellectual impairment and to evaluate the influence of physical and mental dysfunction on occupational status. To our knowledge, a thorough assessment of these parameters has not been carried out previously.

Only three patients had more severe neurological deficits. The epilepsy was acceptably treated in all eight patients as the seizure frequency was less than one seizure every 6 months and thus in no way disabling.

The following factors might be of importance in the development of intellectual impairment in patients with cerebral AVM.

(1) Sequelae from haemorrhage (for example cerebral infarction, hydrocephalus).

(2) Steal-phenomena caused by increased blood-flow in the AVM resulting in insufficient blood-flow in other parts of the brain.

(3) Frequent and severe epileptic seizures.

(4) Type of initial symptom and initial level of consciousness.

(5) Duration of symptoms.

(6) Age at the time of onset of symptoms.

Ten patients had signs of slight intellectual 
impairment and only five had more severe impairment (in two of these patients the severe intellectual dysfunctioning may be related to drug and alcohol abuse). Thus, our results show that severe intellectual deficits are rare in AVM patients, and this conclusion is supported by both the results of Waltimo and Putkonen $^{15}$ and Constans and Assal. ${ }^{16}$ However, differences in patient populations and neurophychological methods make detailed comparisons with our results unreasonable.

In four of the five patients with more severe intellectual impairment CT findings may partially or fully explain the intellectual deficits (one patient with hydrocephalus and three patients with diffuse cerebral atrophy). Apart from this, no relation was found between general intellectual impairment and the above mentioned factors.

Fifteen patients showed signs of specific cognitive dysfunctions. Twelve of these showed the expected relation between the type of dysfunction and anatomical site of the lesion. Lack of relation between cognitive dysfunctions and the site of the lesion may be caused by steal-phenomena.

The occupational status of 19 patients seemed unaffected by deficits in their physical and intellectual functioning while six patients received disablement pension because of sequelae of AVM. It should be noted that three patients with severe intellectual impairment did not receive disablement pension.

We have performed a thorough physical, psychological and social evaluation of 25 relatively unselected patients with unoperated AVM. From our results we must conclude that only about $25 \%$ of these patients will be socially disabled in the long run, $10 \%$ because of physical dysfunction and $15 \%$ because of both physical and psychological dysfunctions. These fairly good results should be considered when evaluating the indication for operation in patients with AVM.

A systematic neuropsychological comparison of surgically and conservatively treated patients would indeed increase our knowledge of the factors of importance in dealing with the difficult question, when should there be surgical or conservative treatment of patients with cerebral arteriovenous malformation.

This study was supported by the Danish Medical Research Council.

\section{References}

1 Svien HJ, McRae JA. Arteriovenous anomalies of the brain. Fate of patients not having definite surgery. $J$ Neurosurg 1965;23:23-8.

2 Troupp $\mathrm{H}$. Arteriovenous malformations of the brain. Prognosis without operation. Acta Neurol Scand
1965;41:39-42.

3 Moody RA, Poppen JL. Arteriovenous malformations. $J$ Neurosurg 1970;32:503-11.

4 Morello G, Borghi GP. Cerebral angiomas. A report of 154 personal cases and a comparison between the results of surgical excision and conservative management. Acta Neurochir 1973;28:135-55.

5 Trumpy JH, Eldevik P. Intfacranial arteriovenous malformations: conservative or surgical treatment? Surg Neurol 1977;8:171-5.

6 Pelletieri L. Surgical versus conservative treatment of intracranial arteriovenous malformations. Acta Neurochir 1980;suppl 29:1-36.

7 Guidetti B, Delitala A. Intracranial arteriovenous malformations. Conservative and surgical treatment. J Neurosurg 1980;53:149-52.

8 Abad JM, Alvarez F, Manrique M, Garcia -Blazquez M. Cerebral arteriovenous malformations. Comparative results of surgical v.s. conservative treatment in 112 cases. J Neurosurg Sci 1983;27:203-10.

9 Fults D, Kelly DL. Natural history of arteriovenous malformations of the brain: A clinical study. Neurosurgery 1984;15:658-62.

10 Perret G, Nishioka H. Report on the Cooperative Study of Intracranial Aneurysms and Subarachnoid Hemorrhage. Section VI. Arteriovenous malformations. An analysis of 545 cases of cranio-cerebral arteriovenous malformations and fistulae reported to the Cooperative Study. J Neurosurg 1966;25:467-90.

11 Iansek R, Elstein AS, Balla JI. Application of decision analysis to management of cerebral arteriovenous malformation. Lancet 1983;i:1132-5.

12 Graf CJ, Perret GE, Torner JC. Bleeding from cerebral arteriovenous malformations as part of their natural history. J Neurosurg 1983;58:331-7.

13 Crawford PM, West CR, Chadwick DW, Shaw MDM. Arteriovenous malformations of the brain: natural history in unoperated patients. $J$ Neurol Neurosurg Psychiatry 1986;49:1-10.

14 Lange-Cosack H. Psychische Storungen beim arteriovenosen Rankenangiom des Gehirns. Dische $Z$ Nervenheilkunde 1954;271:426-42.

15 Waltimo O, Putkonen A-R. Intellectual performance of patients with intracranial arteriovenous malformations. Brain 1974;97:511-20.

16 Constans JP, Assal G. Evolution de la symptomatologie neuropsychologique d'une serie d'anevrismes arterioveineux operés. Neurochirurgia 1971;14:201-16.

17 Carter LP, Morgan M, Urrea D. Psychological improvement following arteriovenous malformation excision. J Neurosurg 1975;42:452-6.

18 Petersen J. Andersen EB, Dige-Petersen H, Ahlgren P, Mortensen EL. Intravenous radionuclide angioscintigraphy and computer tomography in cerebral arteriovenous malformations. Acta Neurol Scand 1983;suppl 94:49-56.

19 Rigshospitalet, neuropsykologisk afsnit. Udvidet neuropsykologisk undersøgelse: Manual. 1980.

20 Gade A, Mortensen EL, Bruhn P. Chronic painters syndrome. A reanalysis of psychological test data in a group of diagnosed cases, based on comparisons with matched controls. Acta Neurol Scand 1988;77: 293-306. 